\title{
Are hotel guests bothered by unlucky floor or room assignments?
}

\author{
Stephen Pratt ${ }^{\mathrm{a}, *}$, Ksenia Kirillova ${ }^{\mathrm{b}}$ \\ ${ }^{a}$ The University of the South Pacific, Private Mail Bag, c/-STHM,Private Mail Bag, Suva 0000, Fiji \\ ${ }^{\mathrm{b}}$ School of Hotel and Tourism Management, The Hong Kong Polytechnic University, 17 Science Museum Road, TST East, Kowloon, Hong Kong SAR
}

A R T I C L E I N F O

\section{Keywords:}

Superstition

Hotels

Lucky

Unlucky

Chinese

Culture

Numerology

\begin{abstract}
A B S T R A C T
Superstitious beliefs can guide individuals' decision-making and change behavior. Different cultures believe that some numbers are 'lucky' and other numbers are 'unlucky'. This can have significant business implications. There is little academic research into how these numerology superstitions impact the hotel sector. We conduct a quantitative survey among Chinese and Western hotel guests to determine the extent to which these guests are influenced by numerological superstitions in their hotel floor and hotel room numbering. Socio-demographic, psychographic and situational characteristics are used as explanatory variables. The results show that the Chinese were more likely to engage in superstitious behavior when it comes to feeling uncomfortable and seeking a change from an unlucky hotel floor and room number than Western guests. For the Western cohort, internal (demographic and psychographic) determinants of superstitious behavior are more significant, whereas, in the Chinese cohort, both internal and external (situation, or trip-specific) determinants influence superstitious behavior.
\end{abstract}

\section{Introduction}

Superstitious beliefs are culturally-constructed or idiosyncratic beliefs that one's actions or objects can influence outcomes when no objective influence exists (Kramer and Block, 2011; Simmons and Schindler, 2003). These superstitions vary from culture to culture. For example, in the West, knocking on wood or crossing one's fingers is believed to bring good luck (Damisch et al., 2010; Keinan, 2002). In Chinese culture, several numbers are believed to be lucky or unlucky because they are homophones. For example, the number four is perceived to be unlucky because it sounds like the word 'death.' Conversely, the number eight is perceived as lucky because it sounds like the word for 'wealth'. In Western culture, the number ' 13 ' is perceived to be unlucky. Fear of the number thirteen is known as triskaidekaphobia. Believing in magic, and specifically in superstitions, have accompanied the humankind since the earliest times and helped humans overcome the uncertainty and unknowns of the external world. In his famous work on the Trobriand Islanders, the anthropologist Malinowski (1948) was first to record that Trobriand fishermen relied on magical thinking when important events fell outside their knowledge (e.g. dangerous sea conditions) and when the outcome was uncertain (e.g. safe return to the land). He writes " $[w]$ e do not find magic whenever the pursuit is certain, reliable, and well under the control of rational methods and technological processes. Further, we find magic where the element of danger is conspicuous" (p. 116). Since then, uncertainty, the lack of knowledge and of subsequent control over external events have conceptually underpinned research on superstitious behavior.

Superstitious beliefs are shown to have a large impact on the marketplace. About 900 million USD is lost in business revenue in the US each Friday the 13th because people tend to refrain from going to work or tending a business (Palazzolo, 2005). Chinese businesspeople are often preoccupied with whether the name of a business is lucky. For example, the total number of strokes when writing the business name in the Chinese language or feng shui methods are used to determine whether a name has good or bad luck (Ang, 1997; Schmitt, 1995). Accordingly, Ang (1997) shows that brand names containing "lucky" elements are perceived more favorably by consumers than those containing "unlucky" signs. Unsurprisingly, Li et al. (2016) find than in $68.0 \%$ of brand names of Chinese financial institutions can be categorized as lucky. Working on the sub-conscious level and counter to economic rationality, superstitions affect consumers' expectations of product quality, decision-making process and even product satisfaction, especially in high-risk conditions (Block and Kramer, 2009; Kramer and Block, 2008).

Irrational beliefs continue to influence people when they travel. A USA TODAY/Gallup Poll in 2007 found that about one in 11 (9\%) Americans would be sufficiently bothered by a hotel assigning them to a room on the 13th floor to seek a change of room with another $4 \%$ being

\footnotetext{
* Corresponding author.

E-mail addresses: stephen.pratt@usp.ac.fj (S. Pratt), ksenia.kirillova@polyu.edu.hk (K. Kirillova).
} 
bothered but not prepared to seek a room change (De Lollis, 2007). The Chinese are thought to believe in a largest number of superstitions, with some related directly to hotel stays, e.g. knocking on the room door before entering for the first time (Silverman, 2017; Simmons and Schindler, 2003). De Lollis (2007) further quotes J.W. 'Bill' Marriott Jr., chairman of Marriott International as saying "It was one of the first things I learned: Don't go to 13". In fact, hospitality businesses are aware of potentially damaging effects of superstitious beliefs on guests' comfort. A common practice in hotels, especially those serving Asian guests, is to eliminate the floor numbers 4 or 13 or to substitute those with $3 \mathrm{a}$ and 12a, respectively, or with names such as "Pool floor" (Miastkowski, 2015). Yet, these industry practices are mainly intuitionbased and lack guidance from systematic academic studies. Specifically, unlike general consumer research, in which the role of irrational beliefs is acknowledged in both product design evaluation and marketing effectiveness (Li et al., 2016; Wang et al., 2015), what drives consumers' superstitious responses in hospitality and tourism remains unknown.

Conceptually, the hospitality and tourism industry presents a unique context to study superstitious behavior. First, these experiences imply a certain degree of uncertainty and risk because they occur in unfamiliar or less familiar environments, often in locations that are culturally and linguistically different from home (Reisinger and Mavondo, 2005; Sun, 2014). As quality of services cannot be assured in advance, uncertainty also accompanies guests' experience of a hotel stay (Sun, 2014). Second, limited understanding of the local culture, or "the way things are done here" shifts the locus of control away from tourists and towards hospitality and tourism service providers, which, on some occasions, can compromise tourists' self-efficacy (Jin et al., 2016). Locus of control refers to how much an individual believes he or she influences the things that happen in life (Huang and Teng, 2009). Comparative to routine-ingrained home environments, uncertainty-laden tourism and hospitality consumptive occasions could be fertile grounds for superstitious behavior to flourish.

According to Vaidyanathan et al. (2018), superstitious behavior has three baseline functions: 1) instrumental, 2) protective, and 3) socialadjustive. First, it promotes an illusion of control by providing explanations and reasons for phenomena that otherwise are unfamiliar or inexplicable, making one's world more predictable and understandable. By means of superstitious beliefs, individuals may produce solutions that increase their control over a situation. Second, individuals engage in superstitious behavior because it serves an ego-protective function even when there is little belief in its effectiveness. In some situations, magical thinking may become a self-fulfilling prophecy, and thus a magical ritual or a belief that a hotel room is lucky may increase optimism, decrease stress, and improve an overall experience (Keinan, 2002). Finally, people may perform superstitious rituals to simply meet the expectations of their social group and to achieve the sense of belongingness. Altogether, it is thus suggested that, although people appear to believe in instrumentality of superstitions, more complex mechanisms may underlie their superstitious behavior.

Partially building off this conceptualization, we develop the threedimensional framework consisting of socio-demographic, psychometric, and situational (trip characteristics) aspects to uncover predictors of numerological superstitious consumer behavior in hospitality. We then empirically test the model with 400 Western tourists and 403 Mainland Chinese tourists to determine the factors that best explain the likelihood of superstitious behavior in terms of hotel room numbers and hotel floor numbers. The findings are hoped to provide a much-needed guidance to the hospitality industry on how to identify a potentially superstitious guest, when and under which conditions guests may behave in a superstitious manner. With these insights, the industry is hoped to become more considerate of guests' irrational yet influential needs and be able to prevent guests' discomfort derived from an unfortunate floor and room assignment, thus helping to ensure service quality and guest satisfaction.

\section{Literature review and hypothesis development}

Superstitions give an illusion of causality: an example of where people develop a belief that two events are causally connected when in fact they are unrelated (Matute et al., 2015). Matute et al. (2015) argue that, along with personal beliefs and pseudoscience, there is a growing worldwide tendency to trust these heuristics. Yet while there is an increasing reliance on superstitions in decision-making, those not holding these superstitions exhibit a negative attitude and lower affiliation intentions towards others holding socially-shared superstitious behaviors (Wang et al., 2014). Wang et al. (2014) find students from the East are more superstitious than students from the West. The lesson for marketers is to take into account the superstitions, especially those related to products and services and the marketing of the same.

Several streams of literature have appeared in the business literature for explaining the antecedents and consequences of holding superstitious beliefs (Vaidyanathan et al., 2018). First, superstitious behavior can be thought of as a dispositional trait: as a function of demographic and socioeconomic differences (e.g. gender, educational background) and as function of personality traits (e.g. need for learning, belief in fate). Second, superstitious beliefs can be a result of cognitive failures such as when caused by faulty associations and as the by-product of adaptive learning (e.g. search for patterns). Finally, superstitions can be understood as a coping mechanism in situations characterized by high degrees of uncertainly, risk, and stress when individuals have the need act as active participants rather than passive observers. Broadly, these antecedents can be categorized into three areas: socio-demographics, psychographic, and situational variables, based on which we propose the conceptual framework presented in Fig. 1. In what follows and using the framework as a backdrop, we develop the hypotheses and research questions to predict the likelihood of Chinese and Western hotel guests' being bothered if assigned to an unlucky floor or room.

\subsection{Socio-demographics}

Mowen and Carlson (2003) test whether demographics can explain superstitious beliefs but find no evidence that education level or gender are associated with superstition. In contrast, Huang and Teng (2009) find, among their Chinese sample, that women are more superstitious than men, especially with respect to their traditional customs and horoscopes dimensions. This finding is supported by Tobacyk and Milford (1983), Orenstein (2002) and Wiseman and Watt (2004). Vaidyanathan et al. (2018) also suggest that women may engage in superstitious behavior for "protective" reasons, with little actual belief in the effectiveness of superstitions. Women and especially solo traveling women generally feel more vulnerable and at risk when in unfamiliar locations (Yang et al., 2018). Even they may not openly endorse the superstitious beliefs, women may choose to act superstitiously to maintain their peace of mind. Anticipated counterfactual thinking (what could have, would have, or should have happened) (Kahneman and Tversky, 1982) in the face of uncertainly could prompt them to engage in superstitious rituals. Therefore, we develop the following hypothesis:

H1a. Women are more likely than men to be bothered if assigned to an "unlucky" hotel floor

H1b. Women are more likely than men to be bothered if assigned to an "unlucky" hotel room

Several scholars have examined the relationship between age and superstition. It is generally hypothesized that younger people are more likely to believe in superstitions as they're open to new ideas (Orenstein, 2002; Torgler, 2007). Younger people feel more uncertain about the future and perceive a lack of control about the future and hence are open to search for alternatives. Following superstitions can 


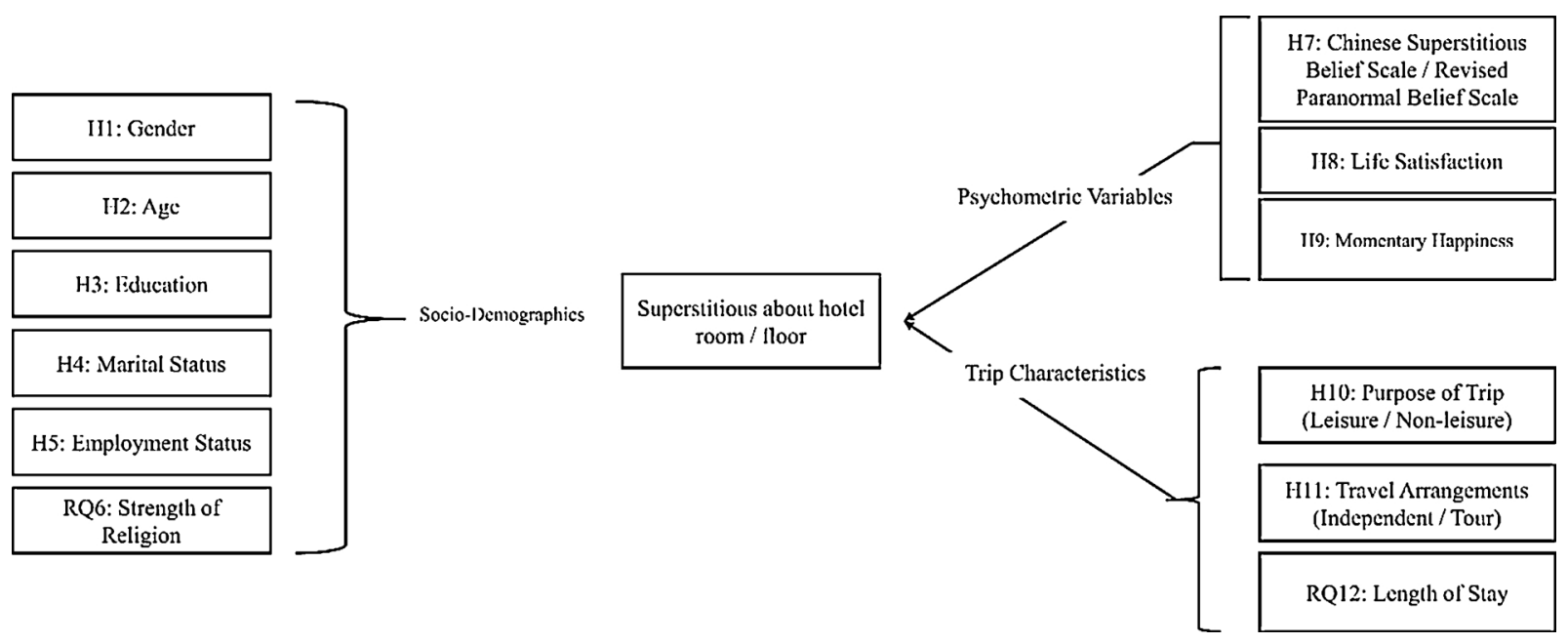

Fig. 1. Conceptual Framework.

help allay concerns about the future and guide decision-making in the face of uncertainty (Malinowski, 1948). Younger people might be more easily swayed by superstitions as they search for meaning and their place in society (MacDonald, 1995). In terms of the latter, younger individuals may engage in superstitious rituals for social-adjustive reasons (Vaidyanathan et al., 2018). They are more likely to seek the sense of social belongingness than older people (Victor and Yang, 2012) and thus may act superstitiously to signal that he/she does not see socially accepted superstitious behavior as irrational. Furthermore, due to limited life experience, they are more likely to adopt the socially accepted behavior without questioning it. This leads to the following hypotheses:

H2a. Younger individuals will be more likely to be bothered if assigned to an "unlucky" hotel floor

H2b. Younger individuals will be more likely to be bothered if assigned to an "unlucky" hotel floor

The more knowledgeable individuals are, the less superstitious they tend to be (Barro and McCleary, 2002). Aarnio and Lindeman (2005) show that university students hold less paranormal beliefs than vocational school students. They attribute this to university students' training in analytical thinking. As superstitions involve attributing an outcome to an incorrect cause (Hanks et al., 2016), those who have attained a higher level of education may be more likely to think critically about different cause and effects. This leads to the following hypotheses:

H3a. Individuals with a higher level of education will be less likely to be bothered if assigned to an "unlucky" hotel floor

H3b. Individuals with a higher level of education will be less likely to be bothered if assigned to an "unlucky" hotel room

We use the concept of relative deprivation as a basis to determine whether marital status influences superstitious beliefs. Relative deprivation is a perceived social or economic comparative disadvantage (Smith et al., 2012). This idea is related to the concept of perceived control or, "the perceived ability to significantly alter events" (Burger, 1989 , p. 246), which tends to be negatively associated with psychological distress (Bárez et al., 2009). Individuals in less socially desirable life situations, or, in other words, "relatively deprived," tend to have a variety of negative psychological responses, ranging from frustration to negative self-identification (Abrams et al., 1999). Deprivation theory predicts that to cope with the psychological and physical strains of being disadvantaged, individuals use beliefs in the paranormal, including superstitions, to cope with psychological discomfort (Rice,
2003; Stark and Bainbridge, 1980). For example, Torgler (2007) tests to see whether those in difficult life situations use superstitions as a sort of 'spiritual help'. Torgler (2007) finds that widowed, divorced and separated people are more superstitious than single individuals, confirming earlier findings by Orenstein (2002) that divorced individuals are more likely to hold beliefs in the paranormal. These insights are also supported by Vaidyanathan et al.'s (2018) proposition that people in disadvantages situations may have a higher need to use superstitions to benefit from its protective function. Widowed, divorced, or single individuals might be more superstitious in hopes to protect themselves from unforeseen and uncontrollable consequences due to unlucky floor/room assignments. We thus hypothesize:

H4a. Separated, widowed or divorced people are more likely to be bothered if assigned to an "unlucky" hotel floor

H4b. Separated, widowed or divorced people are more likely to be bothered if assigned to an "unlucky" hotel room

Along the same lines and through the lens of the deprivation theory, we consider students and unemployed individuals as relatively deprived. While the unemployed may be in a less economically and socially desirable position, students regularly face the pressures of testing and examinations to assure their social status later in life. As a result, the two groups of guests are under greater psychological discomfort than other individuals (Axelsson and Ejlertsson, 2002), and superstitious behavior can be one helpful coping strategy. For instance, Torgler (2007) finds that unemployed individuals are more superstitious than full-time employed people. Given the invisible and uncontrollable consequences of unlucky hotel floor and room assignment, these relatively deprive individuals may also take up superstitious rituals to act as a protective "buffer" between themselves and potential regret associated with a negative event had they not performed a superstitious ritual (Vaidyanathan et al., 2018).

From another perspective, the so called "uncertainty hypotheses," the more people attribute outcomes to uncontrollable forces, the more likely they behave in a superstitious manner (Burger and Lynn, 2005; Felson and Gmelch, 1979). By behaving superstitiously, the person is trying to transform some of the uncontrollable forces into controllable forces to ultimately increase the chances of obtaining a desirable outcome. Case et al. (2004) conduct two studies with undergraduate students and conclude that, under condition of uncertainty and stress, superstitious strategies can be seen as attempts at secondary control, or a feeling of control when actual control is perceived as unattainable. This means that, in addition to protective functions, superstitious behavior can be sought out for its instrumental properties (Vaidyanathan 
et al., 2018). Burger and Lynn (2005) report that superstitious behavior is widespread among baseball players due to the largely uncertain outcomes of baseball games. Based on deprivation theory and the uncertainty hypothesis, we consider students and unemployed people as being placed in uncertain situations and hypothesize:

H5a. Students and unemployed people are more likely to be bothered if assigned to an "unlucky" hotel floor

H5b. Students and unemployed people are more likely to be bothered if assigned to an "unlucky" hotel room

The relationship between religion and belief in the paranormal including superstitions is complex Scholars have explored whether having a religious preference, the strength of religious preference and religious behavior (such as attending places of worship) have an impact on holding paranormal beliefs. Empirical results have been mixed (Orenstein, 2002). Goode (2000) argues that there should be a positive relationship between religion and paranormal beliefs as both involve believing in a philosophical system that defy the laws of science but Emmons and Sobal (1981) find that those individuals identifying with no religion are more likely to believe in the supernatural than those with a religious affiliation. Fox (1992) found to the contrary. Tobacyk and Milford (1983) note that strong religious belief was more associated with witchcraft and precognition but not significantly associated with telepathy and degree of superstition. In terms of strength of religiosity, again findings are inconclusive. Zinnbauer et al. (1997) find those individuals with a stronger degree of religiosity are less likely to believe superstitions and other paranormal beliefs. In contrast, Orenstein (2002) notes that greater religious belief is strongly associated with greater paranormal beliefs, supporting results from MacDonald (1995). From the above literature, we note that identifying with a religion and the strength of that religion can be an important antecedent to paranormal beliefs, including superstitions but the direction of the influence is uncertain. Therefore, we do not propose specific hypothesis and rather treat the strength of religion as an exploratory variable embedded in two research questions:

RQ6a. Does the strength of religion affect the likelihood of a hotel guest being bothered if assigned to an "unlucky" hotel floor?

RQ6b. Does the strength of religion affect the likelihood of a hotel guest being bothered if assigned to an "unlucky" hotel room?

\subsection{Psychographic variables}

Another strand of research explores the intricate relationship between superstitious beliefs and personality traits. Certain personality traits can lead to superstitious behavior and beliefs (Vyse, 2014). Of the five big personality traits (Goldberg, 1990), Peng et al. (2012) put forward the view that neuroticism, openness, and agreeableness are positively related to superstition. Particularly when making low-involvement decisions, superstitions can be used as a heuristic device, when consumers want to reduce uncertainty and simplify their decision-making (Carlson et al., 2009).

It stands to reason that individuals who believe in the paranormal are more likely to follow superstitions. Superstitions are related to, but are also different from, beliefs in other paranormal phenomena such as poltergeist. Huang and Teng (2009) argue that, for example, feng-shui is an important element of the Chinese superstition belief system. For the Chinese cohort, we use Huang and Teng's (2009) Chinese Superstitious Belief scale and for the Western cohort, we use Tobacyk's (2004) Revised Paranormal Belief Scale (described in detail in the Methodology Section) to measure belief in the paranormal. From the above mentioned literature, we arrive at the following hypotheses:

H7a. The more an individual believes in the paranormal, the higher the likelihood of being bothered if assigned to an "unlucky" hotel floor
H7 b. The more an individual believes in the paranormal, the higher the likelihood to be bothered if assigned to an "unlucky" hotel room

Superstitions play a role to relieve different sorts of inabilities individuals experience in life. Superstitions can be considered as a form of cognitive deficiency due to incomplete information (Abbott and Sherratt, 2011) or related to uncertainty in life (Lindeman and Aarnio, 2007). Padgett and Jorgenson (1982) and many others demonstrate that stressful life conditions, e.g. a harsh economic situation, are associated with magical thinking and superstitious beliefs. As noted above with the deprivation theory and uncertainty hypothesis, superstitions play a role in alleviating psychological discomfort. Therefore, we hypothesize the relationship between life satisfaction and superstitious behavior in the following way:

H8a. Individuals who are less satisfied with their life will be more likely to be bothered if assigned to an "unlucky" hotel floor

H8b. Individuals who are less satisfied with their life will be more likely to be bothered if assigned to an "unlucky" hotel room

Using the context of a sports bar, Hanks et al. (2016) find when advertising has superstitious cues, consumers report higher expectations for their team's performance, more positive attitudes toward the bar, and stronger intent to purchase, as compared to no superstitious cues. Dudley (2000) conducts two experiments to investigate the hypothesis that there is a relationship between negative affect and reported level of paranormal belief. Finding that both experiments show evidence that negative affect is positively correlated with level of paranormal belief, Dudley attributes this to a lack of critical thinking and information processing ability that occurs when the individual experiences negative emotions (MacLeod and Donnellan, 1993). In Keinan's (2002) experiments, even a short priming for a stressful situation in a laboratory setting instigates magic thinking and superstitious behavior such as knocking on wood. We thus hypothesize that the higher the satisfaction with an individual's day, the less likely they will be influenced by superstitions:

H9a. Individuals who are less satisfied with their day will be more likely to be bothered if assigned to an "unlucky" hotel floor

H9b. Individuals who are less satisfied with their day will be more likely to be bothered if assigned to an "unlucky" hotel room

\subsection{Situational characteristics (tourists' trip)}

Mowen and Carlson (2003) note that situational characteristics can influence superstitious behavior. Travel is a situational activity with possibilities for multiple types of risks, both controllable and uncontrollable, most of which fall outside individual tourist's control (Williams and Baláž, 2013). Locus of control refers to how much an individual believes he or she influences the things that happen in life (Huang and Teng, 2009). Tobacyk et al. (1988) demonstrate that individuals who believe in superstitions tend to feel lower interpersonal control, that is, developing and maintaining harmonious interpersonal relationships and therefore are less likely to feel personal efficacy control, that is, the beliefs about an individual's capability to accomplish challenging goals. In this research, we use trip characteristics as proxy for situations that are either control promoting or control decreasing and therefore determining the likelihood of superstitious behavior when it comes to hotel floor and hotel room numbers. We develop hypotheses surrounding three situational characteristics that might potentially influence superstitious behavior: purpose of trip; travel arrangements; and length of stay.

First, business travelers or visiting the destination for another nonleisure purpose are in the destination for a specific reason, which may influence their perception of control. Li et al. (2016) find that those who perceive the lack of control over many facets of their lives, that is, 
with low external locus of control, are more likely to hold superstitious beliefs than those with high internal locus of control. Individuals visiting friends and families do not participate in typical tourist activities or visit popular attraction sites; instead, they become part of hosts' daily life and are involved in grocery shopping, automobile commuting, and dining in local restaurants (McKercher, 1996). Business travelers report much stress when traveling as they are forced to stay in non-preferred hotels with inconvenient locations, fly a non-preferred airline with tiresome departure/arrival times, and they worry about unstable Internet connection preventing the contact with the loved ones at home (Chen, 2017). These constraints can reduce their external locus of control, whereas superstitious beliefs may have the control regaining function (Rudski, 2004; Tobacyk et al., 1988). Also, given that external social influence regulates the experiences of both business tourists and those visiting friends and family, it is also possible that these types of tourists may engage in superstitious behavior to showcase their ingroup belonging (Vaidyanathan et al., 2018).

Conversely, leisure tourists may be in the position to exercise more control over their decisions in a destination - what to eat, what to see, where to go. With a greater opportunity to realize the external locus of control and to increase the sense of perceived control, they are less likely to follow superstitious behavior, all else being equal. Therefore, we hypothesize that:

H10a. Non-leisure tourists are more likely to be bothered if assigned to an "unlucky" hotel floor than leisure tourists

H10b. Non-leisure tourists are more likely to be bothered if assigned to an "unlucky" hotel room than leisure tourists

Second, in the context of tourism, the locus of control can be also represented by the type of travel arrangements that tourists use on their trip. Independent travelers may have more opportunities for external locus of control as these tourists tend to make their own travel arrangements, booking their own hotel, deciding what to do and where to go while in the destination. Yet, since much uncertainty surrounds their decision-making, these individuals may need to make heuristic decisions, or use a cognitive shortcut, to reduce uncertainty when making travel arrangements themselves. Superstitious behavior and magical thinking can provide such a cognitive shortcut, as Tsang (2004) demonstrated with the case of making complex business decisions. In contrast, although tourists on a package trip may feel comfortable with fewer occasions to exercise external control, the uncertainly about travel planning is rather buffered by reliance on reputable travel agencies and operators (Wong and Lau, 2001). Thus, we hypothesize:

H11a. Free independent travelers are more likely to be bothered if assigned to an "unlucky" hotel floor than those on an organized tour

H11b. Free independent travelers are more likely to be bothered if assigned to an "unlucky" hotel room than those on an organized tour

Lastly, there are several reasons why tourists' length of stay may influence the likelihood of being bothered by an unlucky floor number or room number. One reason is that the longer the tourist has to be accommodated in an unlucky room or unlucky floor, the more he /she will be bothered by it. This prediction is based on the aforementioned uncertainly hypothesis and evidence for the relationship between superstitions and locus/desire for control. Conversely, tourists who are accommodated in an unlucky room or unlucky floor for a longer period of time may become less anxious or uncertain as they gain more experience staying in the room or floor and be more comfortable. This suggest length of stay might be negatively related to this superstitious behavior. Alternatively, the relationship between numerological superstition and length of stay might be non-linear. That is, tourists' anxiety (from being exposed to a superstitious element) might rise as over length of stay but dissipate at some point as the tourists "gets use to" nothing bad happening. Given the plausibility of several potential relationships and lack of empirical insights in the existing literature, we propose to treat the length of stay as an exploratory variable, as included in the following research questions:

RQ12a. Does the length of stay impact the likelihood of a guest being bothered if assigned to an "unlucky" hotel floor?

RQ12b. Does the length of stay impact the likelihood of a guest being bothered if assigned to an "unlucky" hotel room?

\section{Method}

\subsection{Research instrument}

To address the research questions, a quantitative survey among hotel guests to Hong Kong was conducted. This survey collects data on the extent to which hotel guests are concerned about being hosted in a room or floor associated with being unlucky. The questionnaire contains three broad sections. One section consists of several psychographic questions about the respondents' attitudes to life as well as paranormal beliefs. A second section comprises of questions relating to travel characteristics and there is a section on demographics.

The dependent variable is taken from the USA TODAY/Gallup Poll study (De Lollis, 2007) which asks hotel guests if they were assigned an unlucky hotel floor number would they be comfortable staying on this floor; not be comfortable staying on this unlucky floor but not request a change; or would be sufficiently bothered to seek a change to another floor. The question is repeated for an unlucky hotel room number. For the Chinese hotel guests, the unlucky numbered floor / room is ' 4 ' while for Western hotel guests, the unlucky numbered floor / room is ' 13 '. Life satisfaction is captured using a single item scale (Cheung and Lucas, 2014), asking 'In general, how satisfied are you with your life?' on a five-point Likert scale where ' 5 ' is 'Very satisfied' and ' 1 ' is 'Very dissatisfied'. Single-item life satisfaction measures performed very similarly compared to the multiple-item Satisfaction with Life scale (Diener et al., 1985). Previous scholars get virtually identical answers to substantive questions regardless of which measure they use. Hence, we opt for the more parsimonious option.

We operationalize momentary happiness by using satisfaction with the individual's day as outlined by Cheung and Lucas (2014). This mood-related variable is asked in the following way: 'Right now, how satisfied are you with your day?' The item response scale is the same as for Life Satisfaction. To measure paranormal beliefs, Tobacyk's (2004) revised paranormal belief scale is used for the sample of Western tourists. This scale has been implemented in a range of contexts, with Western cohorts (Aarnio and Lindeman, 2005; Willard and Norenzayan, 2013). The 26-item revised paranormal belief scale contains seven dimensions: traditional religious belief; Psi (mental telepathy / psychokinesis); witchcraft; superstition, spiritualism; extraordinary life forms; and precognition. For the Asian cohort, the paranormal scale is based on Huang and Teng's (2009) Chinese superstitious belief scale. This scale has also been tried and tested in different Chinese contexts (Kim et al., 2016; Lim and Rogers, 2017). The Chinese superstitious belief scale contains six underlying dimensions: Homonyms; Traditional customs; Power of crystal; Horoscope; Feng-shui; and Luck for gambling.

For the trip-related characteristics, a relatively standard set of questions are used including length of stay, travel party size, travel party composition, purpose of trip, trip arrangements and number of visits to the destination. The socio-demographic variables are also fairly standard including age, gender, highest education level attained, marital status, current employment status. However, we also capture religious affiliation; the extent to which the respondent's parents are religious (five-point Likert scale from 'Not religious at all' to 'Very religious') and the centrality of religiosity scale as a measure of the centrality or importance of religion for an individual. The scale has been applied in more than 100 studies in sociology of religion, psychology of religion and religious studies in 25 countries (Huber \& 
Table 1

Independent Variables used in the Analysis.

\begin{tabular}{|c|c|c|c|}
\hline Concept & & Operationalization & Expected Sign \\
\hline Gender & $\mathrm{H} 1$ & Dummy variable - Men $=0$ (Reference); Women $=1$ & + \\
\hline Age & $\mathrm{H} 2$ & Ordinal Variable - 18-24 years; $25-34$ years; $35-44$ years; 45 years or older & - \\
\hline Education & H3 & Dummy variable - Some college education or below $=0$ (Reference); Bachelor's Degree or above $=1$ & - \\
\hline \multirow[t]{2}{*}{ Marital Status } & $\mathrm{H} 4$ & Dummy variable - Married $=0$ (Reference); Widowed $/$ Divorced $/$ Separated $=1$ & + \\
\hline & $\mathrm{H} 4$ & Dummy variable - Married $=0$ (Reference); Single $=1$ & + \\
\hline \multirow[t]{2}{*}{ Employment Status } & H5 & Dummy variable - Employed or self-employed = 0 (Reference); Student $=1$ & + \\
\hline & H5 & Dummy variable - Employed or self-employed $=0$ (Reference); Unemployed $=1$ & + \\
\hline Strength of Religion & RQ6 & Importance of Religion: $1=$ Not important at all $/$ No religion; $10=$ Extremely important & $?$ \\
\hline Paranormal belief & $\mathrm{H} 7$ & Scalar Variable - Average of Revised Paranormal Scale & + \\
\hline Life Satisfaction & H8 & Interval Variable - Cheung and Lucas (2014)'s 5-Point Likert Scale with $1=$ Very Dissatisfied and $5=$ Very Satisfied & - \\
\hline Momentary Happiness & H9 & Interval Variable - Cheung and Lucas (2014)'s 5-Point Likert Scale with $1=$ Very Dissatisfied and $5=$ Very Satisfied & - \\
\hline Purpose of Trip & H10 & Dummy variable - Leisure $=0$ (Reference); Non-leisure $=1$ & + \\
\hline Travel Arrangements & H11 & Dummy variable - Package tour $=0$ (Reference); Free Independent Traveler $=1$ & + \\
\hline Length of Stay & RQ12 & Scalar Variable - Nights in Hong Kong & $?$ \\
\hline
\end{tabular}

Huber, 2012). For this study, we use a single-item measurement adopted from Gorsuch and McFarland (1972).

\subsection{Sampling}

The survey was conducted among hotel guests to Hong Kong using a professional marketing research company. The Western sample was conducted via interviewer-assisted in-person interviews where potential respondents were approached to complete an interview in commonly frequented tourist spots around Hong Kong. The Chinese sample was completed online with the target population coming from the marketing research company's online panels, one of the largest globally. Potential respondents were informed of the aims of the research and asked to participate. These individuals were also informed that all information would remain confidential, that no individual identifiable data would be revealed and told they had every right to withdraw from the study before or during the survey process without penalty of any kind. Respondents were screened to ensure they were 18 years or above and needed to stay at least one night in a hotel in Hong Kong. A stratified sampling technique was employed to ensure representative samples based on age and gender for the two cohorts. The target population quotas for age and gender for Chinese tourists and Western tourists were obtained from the Hong Kong Tourist Board annual report (Hong Kong Tourism Board, 2017). The age and gender quotas ensure that the sample is representative of the respective tourist populations. The sample size for the Western cohort is $N=400$ and the sample size for the Chinese cohort was $\mathrm{N}=403$. This provided a maximum sampling error of $\pm 4.9 \%$ at a $95 \%$ level of confidence for both samples.

\subsection{Analysis}

Regression analysis is used to test the hypotheses and answer the research questions. Given that the dependent variables are qualitative in nature (not bothered to change room / floor; bothered but will not change; and bothered enough to change), we re-categorize this dependent variable into a binary variable (not bothered and bothered) and use a logistic regression to estimate the model. The logit model takes the form:

$\operatorname{Logit}(p)=\sum \beta_{i} X_{i}+\varepsilon_{i}$ where $p$ is the probability of presence of superstitious behavior (being bothered by unlucky floor / room) and $X i$ are the independent variables. The logit transformation is defined as the logged odds:

$$
\begin{aligned}
\text { odds } & =\frac{p_{i}}{1-p_{i}}=\frac{\text { probability of presence of characterstic }}{\text { probability of absence of characteristic }} \text { and Logit }(p) \\
& =\ln \left(\frac{p_{i}}{1-p_{i}}\right)
\end{aligned}
$$

The logistic regression model estimates parameters that maximize the likelihood of observing the sample values. As outlined the 'Literature Review and Hypothesis Development' section, we specify the following variables in the Logistic Regression model (Table 1).

\section{Findings}

Chinese hotel guests are significantly more likely to be bothered to be assigned to an unluckily numbered hotel floor or hotel room than their Western counterparts. Almost one in 10 Chinese hotel guests would be sufficiently bothered to seek a change to another floor or room while the corresponding figure for Western hotel guests is almost $3 \%$. Conversely, 9 in 10 Western hotel guests would not be concerned about being accommodated on the 13th floor or in a 13th room. Only about half of all Chinese hotel guests would not be concerned about being on the 4th floor or in a room number ending with ' 4 '. Formally, a chi-square test of independence is performed to examine the relation between likelihood of being bothered by the room number and type of tourist (Chinese or Western). The relation between these variables was significant, $\chi^{2}(2, N=803)=143.80, p<.001$. Similarly, for the relation between likelihood of being bothered by the floor number and type of tourist, the chi-square test confirmed the significant difference between the two cohorts $\left(\chi^{2}(2, \mathrm{~N}=803)=165.99, \mathrm{p}<.001\right)$. As shown in Table 2, this applies to unlucky floors as much as it does to unlucky rooms across both cohorts.

In terms of those who are numerically superstitious and those who are not, Table 3 shows a profile of the overall sample characteristics of the two cohorts as well as those cohorts segmented by whether they are bothered by an unlucky hotel floor number and room number or not. Each sample characterizes a representative sample of the target population. As noted above, age and gender were quoted based on tourist population proportions. There were few statistically significant differences in the profile of Western tourists between those who professed to be bothered by numerical superstitions and those who were not bothered.

We first conduct correlation analysis and calculate VIFs among the independent variables for both cohorts to determine the extent of multicollinearity between the explanatory variables. These tables can be found in the Appendix. We note that most of the explanatory variables have weak correlations with each other. Only a few variables are moderate correlations. For example, for the Chinese cohort, again, the correlation between Life Satisfaction and Momentary Happiness is 0.643 . We note the regression results suggest that both of these variables are statistically significant hence are measuring different concepts. All other correlations are less than 0.5. Further, the VIFs range from 1.038 to 1.572 for the Western cohort and from 1.024 to 1.823 for the Chinese cohort, well below the suggested cut-off as recommended by Hair et al. (2010). We conclude multicollinearity is not a major concern. 
Table 2

Likelihood of being bothered by unluckily numbered hotel floor and room.

\begin{tabular}{|c|c|c|c|c|}
\hline & \multicolumn{2}{|l|}{ Chinese Tourists } & \multicolumn{2}{|c|}{ Western Tourists } \\
\hline & Unlucky Floor & Unlucky Room & Unlucky Floor & Unlucky Room \\
\hline I would be comfortable staying on the ... & $49.1 \%$ & $51.1 \%$ & $90.8 \%$ & $89.8 \%$ \\
\hline I would not be comfortable staying on the... but would not request a change & $41.7 \%$ & $37.5 \%$ & $6.8 \%$ & $7.5 \%$ \\
\hline I would be sufficiently bothered to seek a change to another .... & $9.2 \%$ & $11.4 \%$ & $2.5 \%$ & $2.8 \%$ \\
\hline
\end{tabular}

Tables 4 and 5 show the results of the logistic regression for the Western hotel guests and Chinese hotel guests, respectively. Although there is no close analogous statistic in logistic regression to the $\mathrm{R}^{2}$ indicator of overall model fit in OLS, Cox and Snell's $\mathrm{R}^{2}$ and the Nagelkerke $\mathrm{R}^{2}$ provide an approximation. Nagelkerke's $\mathrm{R}^{2}$ will normally be higher than the Cox and Snell measure. For the Western hotel guests' logistic regression, we note that the overall model fit is poor with the indicators of model fit being relatively low at 8.8\% (Cox and Snell) and $19.0 \%$ (Nagelkerke) to explain the probability of being bothered by an unlucky floor and between $9.3 \%$ and $19.2 \%$ to explain the probability of an unlucky floor. Further, the Hosmer \& Lemeshow test ( $p=0.013$ for unlucky floor and $\mathrm{p}=0.256$ for unlucky room) of the goodness of fit suggests the model is not a good fit to the data for an unlucky floor but is a better fit for an unlucky floor. However, the chi-squared statistic on which it is based is very dependent on sample size so the value cannot be interpreted in isolation. The classification table shows that $91.3 \%$ of the cases were correctly classified for unlucky floor and $90.5 \%$ for an unlucky room.

Using the Wald criterion, we note that only the Revised Paranormal Belief Scale is significantly different from zero at the $95 \%$ level of confidence. The interpretation of the odds ratio means that a unit increase in the Revised Paranormal Belief Scale results in the Western

Table 3

Profile of Total Sample; Superstitious and Non-Superstitious Hotel Guests.

\begin{tabular}{|c|c|c|c|c|c|c|c|c|c|c|}
\hline & \multicolumn{5}{|c|}{ Western Cohort } & \multicolumn{5}{|c|}{ Chinese Cohort } \\
\hline & \multirow[b]{2}{*}{ Total } & \multicolumn{2}{|l|}{ Unlucky Floor } & \multicolumn{2}{|l|}{ Unlucky Room } & \multirow[b]{2}{*}{ Total } & \multicolumn{2}{|l|}{ Unlucky Floor } & \multicolumn{2}{|l|}{ Unlucky Room } \\
\hline & & Superstitious & Not & Superstitious & Not & & Superstitious & Not & Superstitious & Not \\
\hline \multicolumn{11}{|l|}{ Demographics } \\
\hline \multicolumn{11}{|l|}{ Gender } \\
\hline Male & $62.0 \%$ & $51.4 \%$ & $63.1 \%$ & $53.7 \%$ & $63.0 \%$ & $40.9 \%$ & $37.6 \%$ & $44.4 \%$ & $39.6 \%$ & $42.2 \%$ \\
\hline Female & $38.0 \%$ & $48.6 \%$ & $36.9 \%$ & $46.3 \%$ & $37.0 \%$ & $59.1 \%$ & $62.4 \%$ & $55.6 \%$ & $60.4 \%$ & $57.8 \%$ \\
\hline \multicolumn{11}{|l|}{ Age } \\
\hline 18-24 years & $10.5 \%$ & $16.2 \%$ & $9.9 \%$ & $14.6 \%$ & $10.0 \%$ & $15.6 \%$ & $16.6 \%$ & $14.6 \%$ & $15.7 \%$ & $15.5 \%$ \\
\hline 25-34 years & $23.8 \%$ & $10.8 \%$ & $25.1 \%$ & $14.6 \%$ & $24.8 \%$ & $32.5 \%$ & $22.4 \%$ & $42.9 \%$ & $23.4 \%$ & $41.3 \%$ \\
\hline $35-44$ years & $21.5 \%$ & $29.7 \%$ & $20.7 \%$ & $26.8 \%$ & $20.9 \%$ & $25.3 \%$ & $30.2 \%$ & $20.2 \%$ & $29.9 \%$ & $20.9 \%$ \\
\hline 45 years or older & $44.3 \%$ & $43.2 \%$ & $44.4 \%$ & $43.9 \%$ & $44.3 \%$ & $26.6 \%$ & $30.7 \%$ & $22.2 \%$ & $31.0 \%$ & $22.3 \%$ \\
\hline \multicolumn{11}{|l|}{ Highest Education Level } \\
\hline High school graduate or below & $12.5 \%$ & $21.6 \%$ & $11.6 \%$ & $19.5 \%$ & $11.7 \%$ & $23.3 \%$ & $18.0 \%$ & $28.8 \%$ & $20.8 \%$ & $25.7 \%$ \\
\hline Some college or trade / vocational training & $18.0 \%$ & $16.2 \%$ & $18.2 \%$ & $17.1 \%$ & $18.1 \%$ & $43.9 \%$ & $51.7 \%$ & $35.9 \%$ & $48.2 \%$ & $39.8 \%$ \\
\hline Bachelor's degree or above & $69.5 \%$ & $62.2 \%$ & $70.2 \%$ & $63.4 \%$ & $70.2 \%$ & $32.8 \%$ & $30.2 \%$ & $35.4 \%$ & $31.0 \%$ & $34.5 \%$ \\
\hline \multicolumn{11}{|l|}{ Marital Status } \\
\hline Single, never married & $35.8 \%$ & $32.4 \%$ & $36.1 \%$ & $41.5 \%$ & $35.1 \%$ & $22.1 \%$ & $19.5 \%$ & $24.7 \%$ & $17.8 \%$ & $26.2 \%$ \\
\hline Married or domestic partnership & $57.8 \%$ & $62.2 \%$ & $57.3 \%$ & $53.7 \%$ & $58.2 \%$ & $76.4 \%$ & $78.0 \%$ & $74.7 \%$ & $79.7 \%$ & $73.3 \%$ \\
\hline Widowed / Divorced / Separated & $6.5 \%$ & $5.4 \%$ & $6.6 \%$ & $4.9 \%$ & $6.7 \%$ & $1.5 \%$ & $2.4 \%$ & $0.5 \%$ & $2.5 \%$ & $0.5 \%$ \\
\hline \multicolumn{11}{|l|}{ Employment Status } \\
\hline Student & $8.3 \%$ & $16.2 \%$ & $7.4 \%$ & $19.5 \%$ & $7.0 \%$ & $10.2 \%$ & $8.3 \%$ & $12.1 \%$ & $8.1 \%$ & $12.1 \%$ \\
\hline Self employed & $19.5 \%$ & $24.3 \%$ & $19.0 \%$ & $19.5 \%$ & $19.5 \%$ & $16.4 \%$ & $19.5 \%$ & $13.1 \%$ & $17.3 \%$ & $15.5 \%$ \\
\hline Employed full-time / part-time & $57.0 \%$ & $45.9 \%$ & $58.1 \%$ & $43.9 \%$ & $58.5 \%$ & $70.5 \%$ & $69.8 \%$ & $71.2 \%$ & $72.6 \%$ & $68.4 \%$ \\
\hline Unemployed or Retired & $15.3 \%$ & $13.5 \%$ & $15.4 \%$ & $17.1 \%$ & $15.0 \%$ & $3.0 \%$ & $2.4 \%$ & $3.5 \%$ & $2.0 \%$ & $3.9 \%$ \\
\hline Strength of Religion(Mean: 10-Point Scale & 3.96 & 4.54 & 3.90 & 4.93 & 3.85 & 5.64 & 5.87 & 5.40 & 5.88 & 5.41 \\
\hline \multicolumn{11}{|l|}{ Psychographics } \\
\hline $\begin{array}{l}\text { Revised Paranormal Scale / Chinese Superstition Scale(Mean: } \\
7 \text { Point Scale) }\end{array}$ & 2.66 & 3.50 & 2.58 & 3.45 & 2.57 & 5.00 & 5.07 & 4.93 & 5.13 & 4.88 \\
\hline Life Satisfaction(Mean: 5-Point Scale) & 4.39 & 4.24 & 4.41 & 4.32 & 4.40 & 4.15 & 3.92 & 4.38 & 3.92 & 4.36 \\
\hline Momentary Happiness(Mean: 5-Point Scale) & 4.33 & 4.22 & 4.34 & 4.24 & 4.34 & 4.18 & 3.99 & 4.39 & 3.96 & 4.40 \\
\hline \multicolumn{11}{|l|}{ Travelgraphics } \\
\hline \multicolumn{11}{|l|}{ Purpose of Trip } \\
\hline Recreation, tourism and relaxation & $73.5 \%$ & $75.7 \%$ & $73.3 \%$ & $73.2 \%$ & $73.5 \%$ & $49.6 \%$ & $38.0 \%$ & $61.6 \%$ & $39.1 \%$ & $59.7 \%$ \\
\hline Business reasons & $13.8 \%$ & $8.1 \%$ & $14.3 \%$ & $12.2 \%$ & $13.9 \%$ & $18.6 \%$ & $20.0 \%$ & $17.2 \%$ & $21.8 \%$ & $15.5 \%$ \\
\hline Visiting relatives and friends & $8.3 \%$ & $16.2 \%$ & $7.4 \%$ & $14.6 \%$ & $7.5 \%$ & $21.1 \%$ & $25.4 \%$ & $16.7 \%$ & $24.9 \%$ & $17.5 \%$ \\
\hline Other & $4.6 \%$ & $0.0 \%$ & $5.0 \%$ & $0.0 \%$ & $5.0 \%$ & $10.6 \%$ & $16.5 \%$ & $4.5 \%$ & $14.2 \%$ & $7.3 \%$ \\
\hline \multicolumn{11}{|l|}{ Travel Arrangements } \\
\hline Organized by a travel agency / tour operator & $19.5 \%$ & $13.5 \%$ & $20.1 \%$ & $12.2 \%$ & $20.3 \%$ & $57.3 \%$ & $54.6 \%$ & $60.1 \%$ & $53.3 \%$ & $61.2 \%$ \\
\hline Organized independently & $80.5 \%$ & $86.5 \%$ & $79.9 \%$ & $87.8 \%$ & $79.7 \%$ & $42.7 \%$ & $45.4 \%$ & $39.9 \%$ & $46.7 \%$ & $38.8 \%$ \\
\hline \multicolumn{11}{|l|}{ Trips to Hong Kong } \\
\hline First time & $55.8 \%$ & $48.6 \%$ & $56.5 \%$ & $46.3 \%$ & $56.8 \%$ & $7.9 \%$ & $5.4 \%$ & $10.6 \%$ & $4.6 \%$ & $11.2 \%$ \\
\hline Repeat & $44.3 \%$ & $51.4 \%$ & $43.5 \%$ & $53.7 \%$ & $43.2 \%$ & $92.1 \%$ & $94.6 \%$ & $89.4 \%$ & $95.4 \%$ & $88.8 \%$ \\
\hline Travel Party Size (Mean) & 2.59 & 2.76 & 2.58 & 2.56 & 2.60 & 3.82 & 3.87 & 3.76 & 3.99 & 3.66 \\
\hline Length of Stay (Mean Nights) & 5.86 & 5.89 & 5.86 & 5.78 & 5.87 & 6.88 & 6.55 & 7.22 & 6.10 & 7.63 \\
\hline
\end{tabular}

N.B. Bold represents a statistically significant difference between adjacent columns at the $95 \%$ level of confidence. 
Table 4

Results of Logistic Regression: Western Cohort.

\begin{tabular}{|c|c|c|c|c|c|c|c|c|}
\hline \multirow[t]{2}{*}{ Dependent Variable } & \multicolumn{4}{|c|}{ Unlucky Floor } & \multicolumn{4}{|c|}{ Unlucky Room } \\
\hline & Odds Ratio & Beta Coeff. & S.E & p-Value & Odds Ratio & Beta Coeff. & S.E & p-Value \\
\hline Constant & 0.31 & -1.16 & 1.99 & 0.56 & $0.01^{k * k}$ & -4.42 & 1.88 & 0.02 \\
\hline Gender $($ Female $=1)$ & 1.26 & 0.23 & 0.38 & 0.54 & 1.14 & 0.13 & 0.37 & 0.72 \\
\hline Age (Reference $=18-24$ years) & 0.00 & 0.00 & 0.00 & 0.26 & 0.00 & 0.00 & 0.00 & 0.22 \\
\hline Age $(25-34$ years $=1)$ & 0.28 & -1.26 & 0.82 & 0.12 & 0.83 & -0.19 & 0.76 & 0.80 \\
\hline Age $(35-44$ years $=2)$ & 0.94 & -0.07 & 0.80 & 0.93 & 2.79 & 1.03 & 0.78 & 0.19 \\
\hline Age $(45$ years or older $=3$ ) & 0.63 & -0.47 & 0.79 & 0.55 & 2.15 & 0.77 & 0.75 & 0.31 \\
\hline Education (Bachelor's Degree or above $=1$ ) & 0.81 & -0.21 & 0.40 & 0.61 & 0.86 & -0.16 & 0.39 & 0.69 \\
\hline Widowed, Divorced, Separated & 0.80 & -0.23 & 0.85 & 0.79 & 0.88 & -0.13 & 0.82 & 0.87 \\
\hline Single & 0.73 & -0.32 & 0.50 & 0.53 & 1.70 & 0.53 & 0.46 & 0.25 \\
\hline Student & 2.50 & 0.92 & 0.71 & 0.20 & $5.17^{\text {k* }}$ & 1.64 & 0.65 & 0.01 \\
\hline Unemployed & 1.02 & 0.02 & 0.59 & 0.97 & 1.65 & 0.50 & 0.52 & 0.34 \\
\hline Strength of Religion & 1.01 & 0.01 & 0.10 & 0.93 & 1.10 & 0.10 & 0.07 & 0.15 \\
\hline Revised Paranormal Belief Scale & $2.07^{* * *}$ & 0.73 & 0.17 & 0.00 & $1.91^{* *}$ & 0.65 & 0.16 & 0.00 \\
\hline Life Satisfaction & 0.63 & -0.46 & 0.37 & 0.21 & 0.98 & -0.03 & 0.35 & 0.94 \\
\hline Momentary Happiness & 0.72 & -0.33 & 0.31 & 0.30 & 0.69 & -0.38 & 0.30 & 0.22 \\
\hline Purpose of Trip (Non-leisure $=1$ ) & 0.66 & -0.42 & 0.45 & 0.36 & 1.02 & 0.02 & 0.42 & 0.97 \\
\hline Travel Arrangements(Free Independent Traveler $=1$ ) & 1.79 & 0.58 & 0.57 & 0.31 & 1.91 & 0.65 & 0.56 & 0.25 \\
\hline Party Size & 1.03 & 0.03 & 0.05 & 0.58 & 1.01 & 0.01 & 0.05 & 0.88 \\
\hline Length of Stay & 1.01 & 0.01 & 0.03 & 0.63 & 1.01 & 0.01 & 0.03 & 0.72 \\
\hline Log Likelihood & 209.959 & & & & 225.483 & & & \\
\hline Hosmer and Lemeshow Test $(\mathrm{p}=)$ & 0.103 & & & & 0.256 & & & \\
\hline Nagelkerkes R2 & 0.190 & & & & 0.192 & & & \\
\hline Cox \& Snell R2 & 0.088 & & & & 0.093 & & & \\
\hline Classified Correctly & $91.3 \%$ & & & & $90.5 \%$ & & & \\
\hline
\end{tabular}

S.E $=$ Standard Error.

* $\mathrm{p}<0.1$.

$\mathrm{p}<0.05$.

hotel guest being 2.07 times more likely to be bothered by an unlucky hotel floor. In terms of predicting the likelihood of a Western hotel guest being bothered by an unlucky room, again belief in the paranormal is a significant predictor as well as being a student. If the Western hotel guest is a student, they are 5.17 times more likely to be bothered by an unlucky hotel room.
The model fit for the Chinese cohort logistic regression was better than for the Western cohort model. The Hosmer and Lemeshow Test reveals that the null hypotheses could not be rejected for both unlucky floor and unlucky room, suggesting a good model fit. The pseudo $\mathrm{R}^{2}$ varied between $19.3 \%$ and $25.8 \%$ for the unlucky floor model and $20.9 \%$ and $27.8 \%$ for the unlucky room model.

Table 5

Results of Logistic Regression: Chinese Cohort.

\begin{tabular}{|c|c|c|c|c|c|c|c|c|}
\hline \multirow[t]{2}{*}{ Dependent Variable } & \multicolumn{4}{|c|}{ Unlucky Floor } & \multicolumn{4}{|c|}{ Unlucky Room } \\
\hline & Odds Ratio & Beta Coeff. & S.E & p-Value & Odds Ratio & Beta Coeff. & S.E & p-Value \\
\hline Constant & 4.59 & 1.52 & 1.06 & 0.15 & 2.06 & 0.72 & 1.08 & 0.50 \\
\hline Gender $($ Female $=1)$ & 1.59 & 0.46 & 0.24 & 0.05 & 1.37 & 0.32 & 0.24 & 0.19 \\
\hline Age (Reference $=18-24$ years) & $0.00^{k * *}$ & 0.00 & 0.00 & 0.01 & $0.00^{*}$ & 0.00 & 0.00 & 0.07 \\
\hline Age $(25-34$ years $=1)$ & 0.55 & -0.60 & 0.38 & 0.12 & 0.65 & -0.44 & 0.38 & 0.25 \\
\hline Age $(35-44$ years $=2)$ & 1.45 & 0.37 & 0.41 & 0.37 & 1.41 & 0.35 & 0.42 & 0.40 \\
\hline Age $(45$ years or older $=3$ ) & 1.23 & 0.21 & 0.41 & 0.61 & 1.30 & 0.26 & 0.41 & 0.53 \\
\hline Education(Bachelor's Degree or above $=1$ ) & 0.73 & -0.31 & 0.27 & 0.24 & 0.75 & -0.29 & 0.27 & 0.29 \\
\hline Widowed, Divorced, Separated & 3.50 & 1.25 & 1.16 & 0.28 & 4.84 & 1.58 & 1.17 & 0.18 \\
\hline Single & 0.87 & -0.14 & 0.34 & 0.69 & 0.64 & -0.45 & 0.35 & 0.20 \\
\hline Student & 0.85 & -0.16 & 0.42 & 0.70 & 1.05 & 0.05 & 0.43 & 0.91 \\
\hline Unemployed & 0.92 & -0.09 & 0.69 & 0.90 & 0.73 & -0.32 & 0.73 & 0.66 \\
\hline Strength of Religion & 0.99 & -0.01 & 0.05 & 0.84 & 0.98 & -0.02 & 0.05 & 0.74 \\
\hline Chinese Superstition Scale & $1.52^{k * *}$ & 0.42 & 0.15 & 0.00 & $1.91^{k * k}$ & 0.65 & 0.16 & 0.00 \\
\hline Life Satisfaction & $0.67^{* * *}$ & -0.41 & 0.20 & 0.04 & 0.72 & -0.33 & 0.19 & 0.08 \\
\hline Momentary Happiness & $0.59^{* * *}$ & -0.53 & 0.21 & 0.01 & $0.51^{* *}$ & -0.67 & 0.21 & 0.00 \\
\hline Purpose of Trip (Non-leisure $=1$ ) & $2.35^{k * *}$ & 0.85 & 0.24 & 0.00 & $2.12^{k * *}$ & 0.75 & 0.25 & 0.00 \\
\hline Travel Arrangements(Free Independent Traveler $=1$ ) & 1.25 & 0.23 & 0.25 & 0.37 & $1.51^{*}$ & 0.41 & 0.25 & 0.10 \\
\hline Party Size & 0.98 & -0.02 & 0.02 & 0.42 & 1.00 & 0.00 & 0.02 & 0.90 \\
\hline Length of Stay & 0.99 & -0.02 & 0.02 & 0.39 & $0.96^{k *}$ & -0.04 & 0.02 & 0.03 \\
\hline Log Likelihood & 475.291 & & & & 464.611 & & & \\
\hline Hosmer and Lemeshow Test $(\mathrm{p}=)$ & 0.084 & & & & 0.412 & & & \\
\hline Nagelkerkes R2 & 0.249 & & & & 0.277 & & & \\
\hline Cox \& Snell R2 & 0.187 & & & & 0.208 & & & \\
\hline Classified Correctly & $64.0 \%$ & & & & $67.0 \%$ & & & \\
\hline
\end{tabular}

S.E $=$ Standard Error

$* \mathrm{p}<0.1$

$* * \mathrm{p}<0.05$. 
For the Chinese cohort, several demographic, psychographic and travel graphic variables contribute to explaining the likelihood of a hotel guest being bothered by an unlucky floor or room (Table 5). Females are more likely than males to be bothered by an unlucky floor as well as younger hotel guests. None of the other sociodemographic variables such as strength of religion, employment status, marital status were significant. Further, the three psychographic variables: superstitious beliefs, life satisfaction and momentary happiness are all significant. Those who hold superstitious beliefs are more likely to be bothered by an unlucky floor while those who are less satisfied with their life and those who are less happy with their day were more likely to be bothered by an unlucky floor. Several travel-related variables are statistically significant for both the unlucky floor and unlucky room. Specifically, independent travelers were more likely to bothered by an unlucky room number while hotel guests travelling for non-leisure purposes were more likely to be superstitious about both their 4th floor room and a room number ending in ' 4 '. Those hotel guests with a shorter length of stay are likely to be more superstitious with respect to their unlucky hotel room number. ${ }^{1}$

\section{Discussion \& conclusions}

Uncertainty is an inevitable feature of human experience, and superstitious behavior is one way to minimize this uncertainty in a psychosocially comforting way (Vyse, 2014). On one hand, travel to less familiar environments, often with foreign languages and novel cultural cues, is exciting, which fuels the ever-expanding tourism and hospitality industry. On the other hand, it is a game of chance, somewhat akin to gambling, when quality tourist experiences can never be completely assured and safety is not guaranteed. As such, like other games of chance, tourism is a fertile ground for superstitious behavior. This research was motivated by the need to understand superstitious behavior in tourism in the context of hotel unlucky floor and room assignment for Western and Chinese tourists in Hong Kong. We deconstructed the predictors of such behavior into internal, or trait, (socio-demographic and psychographic determinants) and external (situational) variables.

Overall, the findings show that tourists are concerned, although to varying degrees depending on the cohort (Western vs. Chinese), by presumably unlucky hotel floor and room assignments, and this behavior is equally common among men and women, people with different educational backgrounds, employed and unemployed, single, married, divorced, separated, or windowed individuals, as well as guests with varying degrees of religiosity (Table 6). Furthermore, respondents from both cohorts appear to be more sensitive to an unlucky room rather than floor assignment, particularly when it comes to Chinese independent non-leisure travelers. One possible explanation is that many other guests share the same floor and thus perhaps share the "unlucky effect", minimizing its negative effect on each individual guest and allowing for a greater locus of control. For example, Rittichainuwat (2011) shows that tourists become less concerned about ghosts' presence at a tourism destination as it becomes more crowded with other tourists. Chinese guests with shorter stays were more likely to think superstitiously and request a room change. Longer stays may help alleviate uncertainty about the tourism destination and the quality of associated tourism / service experiences and therefore to reduce the need for superstitious thinking as a way to regain control or to protect oneself.

\footnotetext{
${ }^{1}$ We also tested the whether Length of Stay has a non-linear impact on the likelihood of being bothered by a room or floor with a perceived unlucky number for both Western and Chinese cohorts. For both cohorts, when the square of Length of Stay is include in the models, both Length of Stay and Length of Stay squared are insignificant. These results are available upon request from the authors.
}

Table 6

Summary of Support for Hypothesis Tests.

\begin{tabular}{|c|c|c|c|c|c|}
\hline \multirow[t]{2}{*}{ Hypothesis } & \multirow[t]{2}{*}{ Antecedent } & \multicolumn{2}{|c|}{ Chinese Cohort } & \multicolumn{2}{|c|}{ Western Cohort } \\
\hline & & Floor & Room & Floor & Room \\
\hline H1 & Gender & No & No & No & No \\
\hline $\mathrm{H} 2$ & Age & Yes & Yes & No & No \\
\hline H3 & Education & No & No & No & No \\
\hline $\mathrm{H} 4$ & Marital Status & No & No & No & No \\
\hline H5 & Employment Status & No & No & No & Yes \\
\hline RQ6 & Strength of Religion & No & No & No & No \\
\hline H7 & Paranormal Belief & Yes & Yes & Yes & Yes \\
\hline H8 & Life Satisfaction & Yes & Yes & No & No \\
\hline H9 & Momentary Happiness & Yes & Yes & No & No \\
\hline $\mathrm{H} 10$ & Purpose of Trip & Yes & Yes & No & No \\
\hline H11 & Travel Arrangements & No & Yes & No & No \\
\hline RQ12 & Length of Stay & No & Yes, Negative & No & No \\
\hline
\end{tabular}

Some noteworthy differences emerged in our comparison of Chinese and Western hotel guests. The Chinese were more likely to engage in superstitious behavior when it comes to feeling uncomfortable and seeking a change from an unlucky hotel floor and room number than Western guests. In particular, it was demonstrated that, in the Western cohort, internal determinants of superstitious behavior are more significant, whereas, in the Chinese cohort, both internal (demographic and psychographic) and external (situation, or trip-specific) determinants influence superstitious behavior. The two findings are rather contrary to what would be expected under the uncertainty hypothesis, given that the Chinese culture ranks low in uncertainly avoidance, according to Hofstede's framework (Hofstede Insights.com, 2018). However, this may also mean that, in their superstitious behavior, the Chinese may be more motivated by protective functions of superstitions, driven by hope and anticipated regret, as opposed the fear of a negative event (Vaidyanathan et al., 2018). Lim and Rogers (2017) further note that the Chinese tend to believe in luck as an internal and stable property of a person, while external sources of luck, to which (un)lucky hotel floor and room number would belong, are open to manipulations through culturally and sanctioned practices. Thus, not bothered by and not seeking a change of an unlucky floor and room assignment in hotels might be viewed as non-conformance to socially accepted practices of ensuring one's luck, supporting the idea of socialadjustive function of superstitious behavior (Vaidyanathan et al., 2018).

Papineau (2005) also argues that Chinese linguistic and cultural traditions maintain a luck-oriented worldview, which, combined with a lower locus of control than that of Westerners (Spector et al., 2004), could produce a situation when a Chinese guest chooses to exercise an indirect active control over presumably unlucky circumstances, particularly when unsatisfied with life or being unhappy, as evidenced by our findings. When placed in an unfamiliar environment of a tourism destination, which represents an uncertain event, superstitious behavior as a buffer or even a mood-enhancer could feel particularly comforting. The findings are also in line with Rittichainuwat's (2011) study, in which beliefs in ghosts was a more significant travel barrier to disaster-affected tourism destinations among Asian participants (Thai and Chinese) than among Western tourists (British, Germans, and Americans).

Lower propensity to be bothered by an unlucky floor/room assignment for the Western cohort should be understood not solely as Western guests being inherently less superstitious but also as a strategy of minimize negative social judgement. Existing studies consistently show that people behaving superstitiously are seen by others as uneducated, irrational, and incompetent, resulting in lower affiliative intentions towards such persons (Case et al., 2004; Wang et al., 2014). Unlike the Chinese culture with its built-in luck-enhancing rituals, the Western cultures might be not as accommodating to superstitiousness, from a 
social judgement standpoint. In this case, non-engagement (as opposed to engagement) in superstitious behavior may perform social-adjustive functions for the Western guests (Vaidyanathan et al., 2018).

\subsection{Theoretical and practical implications}

Superstitious thinking and behavior are widespread among humans and are part of most cultural landscapes. The study is the pioneering attempt to empirically address the superstitious behavior and its determinants in tourism and hospitality. Conceptually, it has expanded the view on consumer behavior in tourism and hospitality to include admittedly irrational yet influential beliefs and showed that tourism and hospitality services can be fertile grounds for superstitious behavior. Backed up by Vaidyanathan et al.'s (2018) conceptualization, we reasoned that seeking a hotel floor/room change due to superstitious may not only be motivated by the need to gain control over or to influence an uncertain outcome (instrumental functions), but also by the hopes to minimize anticipated regret (protective functions) and the desire to fit in a social group (social-adjustive functions). Empirical research, however, is required to test the direct effect of these motivation on guests' actual superstitious behavior.

Having deconstructed the predictors into three types (socio-demographic, psychographic, and situational), the study has demonstrated the criticality of guests' cultural backgrounds in the effect of these determinants on superstitious behavior and emphasized that cultural backgrounds may prompt superstitious behavior in hotels for different reasons. Furthermore, this research has highlighted similarities and differences in superstitious behavior between Western and Chinese tourists, arguably the two largest segments of the global travel market.

Aside from the conceptual value, this research provides practical insights for practitioners on how to best identify and accommodate superstitious guests. Hospitality businesses, especially those servings Asian tourists, are aware of potentially damaging effects of superstitious beliefs on guests' comfort, and many eliminate the floor numbers 4 or 13 altogether. This approach, however, may not be appropriate in certain business environments and/or cultural contexts, for which the study can provide further guidance. First, we show that, when it comes to superstitious behavior, most guests should not be profiled based on their gender, marital, employment status, and religious cues. However, clearly, more care needs to be taken when it comes to Chinese tourists as they are more likely to be influenced by superstitions. All else being equal, we suggest that hotels assign a luck-enhancing floor and room number ("8" or those ending with "8") to younger, independently traveling, and business Chinese tourists, particularly when they appear in distress or subpar mood (e.g. a delayed flight). Lucky room numbers (" 7 " for Western and " 8 " $\mathrm{m}$ for Chinese) are advised to be assigned to younger Chinese tourists, Chinese tourists with shorter stays, and Western students. If these characteristics are unclear to hotel employees on the first glance or undetermined in the reservation system, the staff can be trained to ask relevant questions (e.g. "May I know the purpose of your visit to our city?") to determine the possibility for guests to act superstitiously and make floor/room assignments accordingly. Similarly, to aid employees' in their service recovery efforts and to appease distraught guests, lucky floor/room (re)assignment, price discounts or complementary loyalty points that end with " 7 " or " 8 " could be an additional touch demonstrating that a hotel is committed to catering to guests' every, even irrational, need. Second, given that hotel guests may be superstitiously minded for non-instrumental reasons (Vaidyanathan et al., 2018). Some guests may be simply accustomed to act superstitiously without much belief in their effectiveness yet too anxious to give up this behavior, while others act superstitiously feel connected to a group and fit in. To accommodate these guests, rather than eliminating "unlucky" floors and room numbers, hotels may play off guests' superstitiousness by creating the "Club 13" or "Club 4 " to purposefully assign "unlucky" floors/rooms and to provide additional social benefits, e.g. special happy hour discounts for club members, themed afternoon snacks. The idea is to piggyback on guests' need for social belongingness, while creating a unique selling proposition and marketing advantage. Further research is, however, needed to verify the effectiveness of these measures.

\subsection{Limitations and future research}

The study is not free from limitations, which provide avenues for future research. One obvious limitation is that, in assessing one' superstitious behavior, we solely relied on self-report measures, which, given the subject matter, is susceptible to considerable social desirability bias. Future research is invited to cross validate the findings with actual guest behavior as based on hotels' data related to guests' actual questing unlucky floor/room change. Further, our survey questions were designed to imply that if the guest decided to request the floor/ room change as a result of superstitious beliefs, floor/room re-assignment will be a sufficient means to alleviate their irrational concerns. However, whether or not this is actually the case will have to be verified in future studies, with more naturalistic research designs, e.g. field experiment. It should be acknowledged that to maintain cultural sensitivity while preserving construct equivalence (Li, 2014), we operationalized paranormal beliefs by using two different scales (one validated specially for the Chinese respondents and one-specifically for the Western cohort). It is however unclear to which extent respondents from the two cohorts were endorsing comparable paranormal beliefs.

This research focused only on bad-luck numerological superstitious beliefs. Wiseman and Watt (2004), however, show that positive, luckenhancing superstitions are not only prevalent but also psychologically different from bad-luck superstitious. Further, superstitions can be nonnumerological (e.g. red as lucky color in China) and even idiosyncratic (individual-specific). Additional research should clarify the mechanism of luck-enhancing and non-numerological types of superstitious behavior in tourism. Existing evidence that luck-enhancing superstitions produce benefits beyond simple psychological comfort, e.g. improving one's performance (Damisch et al., 2010) and even driving product satisfaction (Kramer and Block, 2011), suggest a potentially important role of consumer's superstitious beliefs in their evaluation of quality of tourism and hospitality products. It would be practically meaningful to examine whether and how superstitions-based room and floor assignments are related to guest satisfaction and loyalty.

Although superstitious beliefs and behaviors are culturally ingrained and socially constructed, it remains unknown whether and how individuals change their superstitions during an extended stay or even a short vacation in a culturally different landscape. In this study, we customized superstition to include a common Western ("13") and a common Chinese ("4") numerological superstition. Future research should adopt an exploratory approach to look into how tourists reconcile their own deep-seated superstitions with those embedded in a destination-specific culture.

\section{Funding information}

The Hong Kong Polytechnic University, Grant/Award Number: G-UABW Hong Kong SAR.

\section{Appendix A. Supplementary data}

Supplementary material related to this article can be found, in the online version, at doi:https://doi.org/10.1016/j.ijhm.2019.03.024.

\section{References}

Aarnio, K., Lindeman, M., 2005. Paranormal beliefs, education, and thinking styles. Pers. Individ. Dif. 39 (7), 1227-1236. https://doi.org/10.1016/j.paid.2005.04.009.

Abbott, K.R., Sherratt, T.N., 2011. The evolution of superstition through optimal use of incomplete information. Anim. Behav. 82 (1), 85-92. 
Abrams, D., Hinkle, S., Tomlins, M., 1999. Leaving Hong Kong?: the roles of attitude, subjective norm, perceived control, social identity and relative deprivation. Int. J. Intercult. Relat. 23 (2), 319-338. https://doi.org/10.1016/S0147-1767(98)00041-8.

Ang, S.H., 1997. Chinese consumers' perception of alpha-numeric brand names. J. Consum. Mark. 14 (3), 220-233. https://doi.org/10.1108/07363769710166800.

Axelsson, L., Ejlertsson, G., 2002. Self-reported health, self-esteem and social support among young unemployed people: a population-based study. Int. J. Soc. Welf. 11 (2), 111-119. https://doi.org/10.1111/1468-2397.00205.

Bárez, M., Blasco, T., Fernández-Castro, J., Viladrich, C., 2009. Perceived control and psychological distress in women with breast cancer: a longitudinal study. J. Behav. Med. 32 (2), 187. https://doi.org/10.1007/s10865-008-9180-5.

Barro, R.J., McCleary, R.M., 2002. Religion and Political Economy in an International Panel NBER Working Paper No. 8931. Retrieved from. http://www.nber.org/ papers/w8931.pdf.

Block, L., Kramer, T., 2009. The effect of superstitious beliefs on performance expectations. J. Acad. Mark. Sci. 37 (2), 161-169. https://doi.org/10.1007/s11747-0080116-y.

Burger, J.M., 1989. Negative reactions to increases in perceived personal control. J. Pers. Soc. Psychol. 56 (2), 246-256.

Burger, J.M., Lynn, A.L., 2005. Superstitious behavior among American and Japanese professional baseball players. Basic Appl. Soc. Psych. 27 (1), 71-76. https://doi.org/ 10.1207/s15324834basp2701_7.

Carlson, B.D., Mowen, J.C., Fang, X., 2009. Trait superstition and consumer behavior: reconceptualization, measurement, and initial investigations. Psychol. Mark. 26 (8), 689-713. https://doi.org/10.1002/mar.20295.

Case, T.I., Fitness, J., Cairns, D.R., Stevenson, R.J., 2004. Coping with uncertainty: superstitious strategies and secondary control. J. Appl. Soc. Psychol. 34 (4), 848-871.

Chen, H.S., 2017. Travel well, road warriors: assessing business travelers' stressors. Tourism Manage. Perspect. 22, 1-6. https://doi.org/10.1016/j.tmp.2016.12.005.

Cheung, F., Lucas, R.E., 2014. Assessing the validity of single-item life satisfaction measures: results from three large samples. Qual. Life Res. 23 (10), 2809-2818. https:// doi.org/10.1007/s11136-014-0726-4.

Damisch, L., Stoberock, B., Mussweiler, T., 2010. Keep your fingers crossed! How superstition improves performance. Psychol. Sci. 21 (7), 1014-1020.

De Lollis, B., 2007. Some hotels don't skip the 13th floor anymore. USA Today. Retrieved from. http://usatoday30.usatoday.com/money/biztravel/2007-03-08-13th-floorusat_N.htm.

Diener, E., Emmons, R.A., Larsen, R.J., Griffin, S., 1985. The satisfaction with life scale. J. Pers. Assess. 49 (1), 71-75. https://doi.org/10.1207/s15327752jpa4901_13.

Dudley, R.T., 2000. The relationship between negative affect and paranormal belief. Pers. Individ. Dif. 28 (2), 315-321. https://doi.org/10.1016/S0191-8869(99)00100-2.

Emmons, C.F., Sobal, J., 1981. Paranormal beliefs: functional alternatives to mainstream religion? Rev. Relig. Res. 22 (4), 301-312. https://doi.org/10.2307/3509764.

Felson, R.B., Gmelch, G., 1979. Uncertainty and the use of magic. Curr. Anthropol. 20 (3), 587-589. https://doi.org/10.1086/202333.

Fox, J.W., 1992. The structure, stability, and social antecedents of reported paranormal experiences. Sociol. Anal. 53 (4), 417-431.

Goldberg, L.R., 1990. An alternative "description of personality": the big-five factor structure. J. Personal. Soc. Psychol.: Personal. Process. Indiv. Diff. 59 (6), 1216-1229.

Goode, E., 2000. Two paranormalisms or two and a half? An empirical exploration. Skeptical Inquirer 24 (1), 29-35.

Gorsuch, R.L., McFarland, S.G., 1972. Single vs. Multiple-item scales for measuring religious values. J. Sci. Study Relig. 11 (1), 53-64. https://doi.org/10.2307/1384298.

Hair, J.F., Black, W.C., Babin, B.J., Anderson, R.E., 2010. Multivariate Data Analysis, 7th ed. Prentice Hall, Upper Saddle River, New Jersey.

Hanks, L., Zhang, L., McGinley, S., 2016. Unconditioned superstition and sports bar fans. J. Hosp. Mark. Manage. 25 (1), 113-131. https://doi.org/10.1080/19368623.2014. 987417.

Hofstede Insights.com, 2018. Hofstede Insights. Retrieved from. https://www.hofstedeinsights.com/.

Hong Kong Tourism Board, 2017. A Statistical Review of Hong Kong Tourism 2016. Retrieved from. http://securepartnernet.hktb.com/filemanager/intranet/ir/ ResearchStatistics/paper/Stat-Review/StatReview2016/Stat\%20Review\%202016. pdf.

Huang, L.-S., Teng, C.-I., 2009. Development of a Chinese superstitious belief scale. Psychol. Rep. 104 (3), 807-819.

Huber, S., Huber, O.W., 2012. The Centrality of Religiosity Scale (CRS). Religions 3 (3), $710-724$.

Jin, X., Wu, L., Becken, S., Ding, P., 2016. How do worry, self-efficacy, and coping interact? Examining chinese tourists to Australia. J. China Tour. Res. 12 (3-4), 374-393. https://doi.org/10.1080/19388160.2016.1251868.

Kahneman, D., Tversky, A., 1982. The psychology of preferences. Sci. Am. 246 (1), $160-173$.

Keinan, G., 2002. The effects of stress and desire for control on superstitious behavior. Pers. Soc. Psychol. Bull. 28 (1), 102-108.

Kim, J., Ahlgren, M.B., Byun, J.-W., Malek, K., 2016. Gambling motivations and superstitious beliefs: a cross-cultural study with casino customers. Int. Gambl. Stud. 16 (2), 296-315. https://doi.org/10.1080/14459795.2016.1182569.

Kramer, T., Block, L., 2008. Conscious and nonconscious components of superstitious beliefs in judgment and decision making. J. Consum. Res. 34 (6), 783-793. https:// doi.org/10.1086/523288.

Kramer, T., Block, L., 2011. Nonconscious effects of peculiar beliefs on consumer psychology and choice. J. Consum. Psychol. 21 (1), 101-111. https://doi.org/10.1016/j. jcps.2010.09.009.

Li, M., 2014. Cross-cultural tourist research: a meta-analysis. J. Hosp. Tour. Res. 38 (1), 40-77. https://doi.org/10.1177/1096348012442542.
Li, H.-H., Hsieh, M.-Y., Chang, W.L., 2016. Lucky names: superstitious beliefs in Chinese corporate branding strategy for bank marketing. North Am. J. Econ. Financ. 35, 226-233. https://doi.org/10.1016/j.najef.2015.10.011.

Lim, M.S.M., Rogers, R.D., 2017. Chinese beliefs in luck are linked to gambling problems via strengthened cognitive biases: a mediation test. J. Gambl. Stud. https://doi.org/ 10.1007/s10899-017-9690-6.

Lindeman, M., Aarnio, K., 2007. Superstitious, magical, and paranormal beliefs: an integrative model. J. Res. Pers. 41 (4), 731-744.

MacDonald, W.L., 1995. The effects of religiosity and structural strain on reported paranormal experiences. J. Sci. Study Relig. 34 (3), 366-376. https://doi.org/10. $2307 / 1386885$.

MacLeod, C., Donnellan, A.M., 1993. Individual differences in anxiety and the restriction of working memory capacity. Pers. Individ. Dif. 15 (2), 163-173. https://doi.org/10. 1016/0191-8869(93)90023-V.

Malinowski, B., 1948. Magic, Science and Religion and Other Essays. The Free Press, Glencoe, Illinois.

Matute, H., Blanco, F., Yarritu, I., Díaz-Lago, M., Vadillo, M.A., Barberia, I., 2015. Illusions of causality: how they bias our everyday thinking and how they could be reduced. Front. Psychol. 6 (888), 1-14. https://doi.org/10.3389/fpsyg.2015.00888.

McKercher, B., 1996. Host involvement in VFR travel. Ann. Tour. Res. 23 (3), 701-703. https://doi.org/10.1016/0160-7383(95)00100-X.

Miastkowski, R., 2015. Very Superstitious: the Truth Behind Hotels' Missing 13th Floors. Retrieved from. https://www.orbitz.com/blog/2015/02/friday-13th-truth-behindhotels-missing-13th-floors/.

Mowen, J.C., Carlson, B., 2003. Exploring the antecedents and consumer behavior consequences of the trait of superstition. Psychol. Mark. 20 (12), 1045-1065. https://doi. org/10.1002/mar.10108.

Orenstein, A., 2002. Religion and paranormal belief. J. Sci. Study Relig. 41 (2), 301-311. https://doi.org/10.1111/1468-5906.00118.

Padgett, V.R., Jorgenson, D.O., 1982. Superstition and economic threat: germany, 1918-1940. Pers. Soc. Psychol. Bull. 8 (4), 736-741. https://doi.org/10.1177/ 0146167282084021.

Palazzolo, R., 2005. Is Friday the 13th a Reason to Stay in Bed? Retrieved from. http:// abcnews.go.com/Health/story? id $=751011$ \&page $=1$.

Papineau, E., 2005. Pathological gambling in Montreal's Chinese community: an anthropological perspective. J. Gambl. Stud. 21 (2), 157-178.

Peng, Y.-S., Hsiung, H.-H., Chen, K.-H., 2012. The level of concern about Feng Shui in house purchasing: the impacts of self-efficacy, superstition, and the big five personality traits. Psychol. Mark. 29 (7), 519-530. https://doi.org/10.1002/mar.20539.

Reisinger, Y., Mavondo, F., 2005. Travel anxiety and intentions to travel internationally: implications of travel risk perception. J. Travel. Res. 43 (3), 212-225. https://doi. org/10.1177/0047287504272017.

Rice, T.W., 2003. Believe it or not: religious and other paranormal beliefs in the United States. J. Sci. Study Relig. 42 (1), 95-106. https://doi.org/10.1111/1468-5906. 00163.

Rittichainuwat, B., 2011. Ghosts: a travel barrier to tourism recovery. Ann. Tour. Res. 38 (2), 437-459.

Rudski, J., 2004. The illusion of control, superstitious belief, and optimism. Curr. Psychol. 22 (4), 306-315. https://doi.org/10.1007/s12144-004-1036-8.

Schmitt, B.H., 1995. Language and visual imagery: issues of corporate identity in East Asia. Columbia J. World Bus. 30 (4), 28-36. https://doi.org/10.1016/0022-5428(95) 90003-9.

Silverman, S., 2017. 10 Chinese travel superstitions. DigMandarin. Retrieved from. https://www.digmandarin.com/chinese-travel-superstitions.html.

Simmons, L.C., Schindler, R.M., 2003. Cultural superstitions and the price endings used in Chinese advertising. J. Int. Mark. 11 (2), 101-111.

Smith, H.J., Pettigrew, T.F., Pippin, G.M., Bialosiewicz, S., 2012. Relative deprivation:a theoretical and meta-analytic review. Personal. Soc. Psychol. Rev. 16 (3), 203-232. https://doi.org/10.1177/1088868311430825.

Spector, P.E., Sanchez, J.I., Siu, O.L., Salgado, J., Ma, J., 2004. Eastern versus Western control beliefs at work: an investigation of secondary control, socioinstrumental control, and work locus of control in China and the US. Appl. Psychol. 53 (1), 38-60.

Stark, R., Bainbridge, W.S., 1980. Towards a theory of religion: religious commitment. J. Sci. Study Relig. 19 (2), 114-128. https://doi.org/10.2307/1386246.

Sun, J., 2014. How risky are services? An empirical investigation on the antecedents and consequences of perceived risk for hotel service. Int. J. Hosp. Manag. 37, 171-179. https://doi.org/10.1016/j.ijhm.2013.11.008.

Tobacyk, J.J., 2004. A revised paranormal belief scale. Int. J. Transpers. Stud. 23 (23), 94-98.

Tobacyk, J.J., Milford, G., 1983. Belief in paranormal phenomena: assessment instrument development and implications for personality functioning. J. Pers. Soc. Psychol. 44 (5), 648-655.

Tobacyk, J.J., Nagot, E., Miller, M., 1988. Paranormal beliefs and locus of control: a multidimensional examination. J. Pers. Assess. 52 (2), 241-246. https://doi.org/10. 1207/s15327752jpa52025.

Torgler, B., 2007. Determinants of superstition. J. Socio. 36 (5), 713-733. https://doi. org/10.1016/j.socec.2007.01.007.

Tsang, E.W., 2004. Superstition and decision-making: contradiction or complement? Acad. Manag. Exec. 18 (4), 92-104.

Vaidyanathan, R., Aggarwal, P., Bakpayev, M., 2018. A functional motivation framework for examining superstitious behavior. J. Assoc. Consum. Res. 3 (4), 454-465. https:// doi.org/10.1086/698492.

Victor, C.R., Yang, K., 2012. The prevalence of loneliness among adults: a case study of the United Kingdom. J. Psychol. 146 (1-2), 85-104. https://doi.org/10.1080/ 00223980.2011 .613875$.

Vyse, S.A., 2014. Believing in Magic: the Psychology of Superstition, Updated ed. Oxford 
University Press, New York.

Wang, D., Oppewal, H., Thomas, D., 2014. Exploring attitudes and affiliation intentions toward consumers who engage in socially shared superstitious behaviors: a study of students in the east and the west. Psychol. Mark. 31 (3), 203-213. https://doi.org/10. 1002/mar.20687.

Wang, Y.J., Hernandez, M.D., Minor, M.S., 2015. Superstitious beliefs in consumer evaluation of brand logos. In: S. H (Ed.), Revolution in Marketing: Market Driving Changes. Developments in Marketing Science: Proceedings of the Academy of Marketing Science. Springer, Cham.

Willard, A.K., Norenzayan, A., 2013. Cognitive biases explain religious belief, paranormal belief, and belief in life's purpose. Cognition 129 (2), 379-391. https://doi.org/10. 1016/j.cognition.2013.07.016.

Williams, A.M., Baláž, V., 2013. Tourism, risk tolerance and competences: travel organization and tourism hazards. Tour. Manag. 35, 209-221. https://doi.org/10. 1016/j.tourman.2012.07.006.

Wiseman, R., Watt, C., 2004. Measuring superstitious belief: why lucky charms matter. Pers. Individ. Dif. 37 (8), 1533-1541.

Wong, S., Lau, E., 2001. Understanding the behavior of Hong Kong Chinese tourists on group tour packages. J. Travel. Res. 40 (1), 57-67.

Yang, E.C.L., Khoo-Lattimore, C., Arcodia, C., 2018. Power and empowerment: how Asian solo female travellers perceive and negotiate risks. Tour. Manag. 68, 32-45. https:// doi.org/10.1016/j.tourman.2018.02.017.

Zinnbauer, B.J., Pargament, K.I., Cole, B., Rye, M.S., Butter, E.M., Belavich, T.G., et al., 1997. Religion and spirituality: unfuzzying the fuzzy. J. Sci. Study Relig. 36 (4), 549-564. https://doi.org/10.2307/1387689. 